\section{CONCLUSIONES}

En las especies $C$. chaniaralensis, E. sandillon y L. aureispinus no hubo respuesta a la formación de callo bajo las condiciones estudiadas. La utilización de $0,1 \mathrm{mgL}^{-1}$ de ANA y $1,0 \mathrm{mgL}^{-1}$ de BAP resultó exitosa para la formación de brotes en C. hypogaea, M.elongata, O. berteri, Opuntia sp. y Trichocereus sp., en tanto que en $N$. napina solo se logró la inducción de callo.

Con el mismo medio y después de una prolongada fase de formación de callo, se logró establecer Cereus peruvianus y Rhipsalidopsis gaertneri.

No fue posible inducir una eficiente formación de raíces en la mayoría de las especies en estudio, con las combinaciones de fitorreguladores empleadas.

\section{REFERENCIAS}

CLAYTON, P., HUBSTENBERGER, J.; PHILLIPS, G. 1990. Micropropagation of members of the Cactaceae subtribe Cactinae. J. Amer. Soc. Hort. Sci. 115(2):337-343.

HOFFMANN, A. 1989. Cactáceas en la flora silvestre de Chile. Santiago, Chile. Fundación Claudio Gay. 272p.

RODRÍGUEZ, C. 2006. Morfogénesis in vitro de nueve especies de interés botánico y ornamental pertenecientes a la familia Cactaceae. Tesis Lic. Agr. Valdivia, Chile. Universidad Austral de Chile.

\title{
PROPAGACIÓN DE Lepidophyllum cupressiforme (Lam.) Cass., UNA ESPECIE NATIVA DE LA PATAGONIA AUSTRAL DE CHILE, CON POTENCIAL ORNAMENTAL *
}

\section{PROPAGATION OF Lepidophyllum cupressiforme (Lam.) Cass., A CHILEAN PATAGONIC SPECIES WITH ORNAMENTAL POTENTIAL}

\author{
Yagello, J. ${ }^{1}$, Vera, M. ${ }^{1}$, Massardo, F. ${ }^{2}$, Dollenz, O. ${ }^{3}$ y Musalem, M. ${ }^{4}$ \\ ${ }^{1}$ Instituto de la Patagonia, \\ ${ }^{2}$ Parque Etnobotánico Omora, UMag - Sede Puerto Williams, \\ ${ }^{3}$ Departamento de Ciencias y Recursos Naturales, \\ Universidad de Magallanes, Casilla 113D, Punta Arenas, Chile. \\ ${ }^{4}$ Vivero Pumahuida, Santiago. \\ E-mail: julio.yagello@umag.cl
}

\section{INTRODUCCION}

Lepidophyllum cupressiforme, es un arbusto de la familia Asteraceae, conocido en la zona de Magallanes como Mata Verde. Su género Lepidophyllum proviene del griego que significa escama y hoja, aludiendo al parecido de las hojas con escamas, cupressiforme se refiere a que se asemeja a un ciprés.

La características de este arbusto es que es siempre verde, de unos $0,6 \mathrm{~m}$ de altura, muy ramificado, erecto, con hojas opuestas escamiformes, imbricadas, glabras, serinosas, elípticas obtusas de 2-3 mm de largo x $2 \mathrm{~mm}$ de ancho. Los capítulos florales son amarillos y la floración ocurre desde noviembre a enero, su fruto es un aquenio ovoide, costado, papiloso áspero en la mitad superior (Moore, 1983).

En relación con su distribución, se presenta en forma endémica formando matorrales de poca extensión en el extremo sur de la Patagonia y Tierra del Fuego. Es una planta 
dominante de suelos costeros con cierto grado de salinidad y se desarrolla entre los 0 y 20 m.s.n.m., especialmente en laderas costeras donde alcanzan una altura de $1.5 \mathrm{~m}$. Es capaz de soportar elevados contenidos salinos en el suelo.

Desde el punto de vista ornamental, la mata verde es una especie resinosa que exhala un agradable e intenso perfume. Este arbusto resulta particularmente llamativo por los atributos de su follaje verde lustroso y resinoso que en un jardín puede producir contrastes muy satisfactorios, proporcionando solidez y continuidad estacional al mantener su color durante toda la temporada. En cuanto a su floración, la mata verde es también interesante ya que a pesar de sus flores minúsculas, su despliegue tiende a agruparlas de tal forma que presentan una masa espesa de color amarillo muy llamativa. Las flores resultan especialmente útiles como realce en jardines rústicos, informales o silvestres, donde se pueda entremezclar con otras plantas que refuercen el efecto de bosque.

El objetivo de este trabajo fue determinar las técnicas de propagación y algunas fases en la domesticación de Lepidophyllum cupressiforme.

\section{MATERIALES Y MÉTODOS}

La recolección de material de Lepidophyllum cupressiforme se realizó en la estepa patagónica, específicamente en el sector de Buque Quemado. (52 $2^{\circ} 15$ '07" 4" S 69 25'55" 2" W. Wentro de la composición florística, Lepidophyllum cupressiforme es la especie principal, abarcando cerca del $70 \%$ de cobertura vegetal.

Según la clasificación de Köppen (Pisano, 1977), el clima del sector corresponde al de Estepa Frío BSk', cuyas precipitaciones anuales van desde 200 a 400 mm sin una estación seca.

\section{RESULTADOS}

La floración de la mataverde ocurre entre noviembre y enero (Moore,1983). Los 10 individuos marcados en el sector seleccionado presentaron escasa floración y fructificación con gran proporción de frutos con semillas noviables en todas las temporadas durante los años 2003 al 2006.

Las semillas, tuvieron un comportamiento muy diferente dependiendo del año de la colecta, no obstante los sitios y épocas de colecta fueron los mismos en todos los casos.

La caracterización de la semilla muestran que la viabilidad de las semillas es bastante baja, si bien es cierto, el tamaño del aquenio hace compleja la determinación de la tinción del TTC adecuadamente. (35,4\%). La germinación natural del $L$. cupressiforme depende de la época de colecta en terreno. El tratamiento de estratificación a distintos tiempos no tuvo efecto sobre la germinación y en el caso de la Temporada 2003, redujo la aparición de radícula probablemente por daño por frío al embrión, con reducción visible del vigor de las plántulas que germinaron una vez concluida la estratificación. La germinación natural comenzó a los 10 días y este tiempo se acortó a 3 días con la estratificación, aunque el frío provocó la germinación prematura y menores porcentajes finales.

No obstante la baja germinación de esta especie los años 2004 a 2006, las plantas producidas por semillas colectadas el año 2003 han tenido muy buena respuesta al crecimiento ex situ.

La mataverde crece como matorral denso monoespecífico asociado con una escasa cubierta herbácea superficial. Debido a esto se sospechó la presencia de compuestos alelopáticos se realizó un bioensayo utilizando semillas de Lepidium sativum como especie indicadora en presencia de extracto de hoja de mataverde Las semillas de L. sativum mostraron imbibición normal pero inhibición de la germinación respecto al control cuando se expuso a extractos de hoja adulta de L. cupressiforme y a extractos de suelo superficial y profundo colectado de los sitios de crecimiento de mataverde. Las pocas semillas que germinaron tuvieron una radícula anormal respecto al control. Se concluyó que $L$. cupressiforme tendría un efecto inhibitorio sobre la germinación de semillas de otras especies y que el compuesto responsable de la alelopatía podría mantenerse en el suelo. Este resultado sugiere que se deben realizar más ensayos en domesticasión para el uso de la mataverde como 
especie ornamental.

Respecto de los ensayos en propagación vegetativa Los esquejes de las plantas madre se colectaron de individuos que mantenían la forma menos defectuosa con poca consistencia resinosa y bastante ramificadas, se seccionaron ramillas muy cerca de la base de la planta, sin terminaciones de capítulos florales con hojas escamiformes sanas y de buen color, con una consistencia no demasiado leñosa ni excesivamente herbácea, los esquejes obtenidos se mantuvieron en diversos sustratos a temperatura ambiente en condiciones de invernadero. Se evaluó la respuesta del enraizamiento al ácido Indol-butírico (IBA) a $\operatorname{los} 30,60,90$ y 120 días, se efectuaron colectas en todas las épocas del año. Los resultados muestran que la mejor época para la colecta de Lepidophyllum cupressiforme es en otoño enraizando a los 60 días con enraizante comercial.

\section{CONCLUSIONES}

Las plantas obtenidas por los ensayos han sido exitosamente trasplantadas al exterior donde se han aclimatado favorablemente. De acuerdo a lo logrado en esta especie, se concluye que Lepidophyllum cupressiforme es una especie nativa chilena muy promisoria para la floricultura ornamental. Sin embargo se debe seguir realizando esfuerzos en poder desarrollar un protocolo de manejo agronómico y domesticación definir su uso productivo en relación a su aptitud ornamental y su evaluación de mercado.

*Trabajo financiado por el Proyecto FIA-PI-C-2002-1-A-070/Universidad de Magallanes

Agro Sur 35 (2): 28-30 2007

\title{
EFECTO DEL PESO DEL BULBO SOBRE EL CRECIMIENTO VEGETATIVO Y REPRODUCTIVO DE Herbertia lahue (Molina) Goldbl. subsp. lahue (Iridaceae))
}

\section{EFFECT OF BULB WEIGHT ON THE VEGETATIVE AND REPRODUCTIVE DEVELOPMENT OF Herbertia lahue (Molina) Goldbl. subsp. lahue (Iridaceae)}

\author{
Morales, P. ${ }^{1}$, Peñailillo, P. $^{2}$, Yañez, P. $^{1}$ y Schiappacasse, F. ${ }^{1}$. \\ ${ }^{1}$ Facultad de Ciencias Agrarias, ${ }^{2}$ Instituto de Biología Vegetal y Biotecnología. \\ Universidad de Talca, Casilla 747, Talca, Chile. \\ E-mail: ppenaili@utalca.cl
}

\section{INTRODUCCIÓN}

La especie Herbertía lahue (Molina) Goldbl., (Iridaceae) está representada en Chile por H. lahue subsp. lahue, la cual crece además en Argentina y Uruguay (Ravenna, 1968; Goldblatt, 1975 y 1978). En Chile, H. lahue subsp. lahue, conocida vernacularmente como "lahue", se distribuye desde la provincia de Valparaíso hasta la provincia de Valdivia. En su hábitat el lahue crece en suelos húmedos, bien drenados y ricos en material orgánica y bajo un clima mediterráneo. El atractivo de su follaje semejando hojas pequeñas de palmera y sus flores delicadas con la apariencia de un lirio en miniatura, hacen del lahue una bulbosa con potencial ornamental (Hoffmann, 1989; Bridgen et al. 2002; Schiappacasse et al., 2003).

La época de floración, permanencia del follaje, propagación vegetativa y por semillas ya han sido abordadas (Schiappacasse et al., 2003, 2005); sin embargo, se carece de otros estudios para su manejo cultural como la influencia que tiene el peso (o tamaño) del 